\title{
EL TIEMPO DE LA REVUELTA; REFLEXIONES EN TORNO AL CONCEPTO DE JETZTZEIT
}

\author{
Por Cristián Sucksdorf \\ A la memoria de León Rozitchner
}

\begin{abstract}
El siguiente trabajo intentará reconstruir la constelación de sentido que forma la "idea" benjaminiana de temporalidad en torno al concepto de Jetztzeit (tiempo-ahora) y su correspondiente forma de subjetividad. A partir de las diferencias con otras formas de "producción" de temporalidad y sus estructuras subjetivas, pasaremos a precisar el funcionamiento interno del concepto de Jetztzeit. Para ello partiremos del contraste de este concepto con el de Jetztsein (ser-actual), en relación a las temáticas del sueño y la infancia bajo la tarea programática del "despertar" (Erwachen). Para hacer visible esta articulación tomaremos prestados los conceptos de Lebenszeit (tiempo de la vida) y Weltzeit (tiempo del mundo) de Hans Blumenberg (1986), aunque sistematizados de un modo diferente al del autor.
\end{abstract}

Palabras-clave: Jetztzeit (tiempo-ahora). Subjetividad. Infancia. Lebenszeit-Weltzeit (tiempo de la vida- tiempo del mundo). Tiempo Común.

\section{THE TIME OF THE REVOLT; THOUGHTS SURROUNDING WALTER BENJAMIN'S JETZTZEIT CONCEPT}

\begin{abstract}
The following paper will try to reconstruct the constellation of sense that forms the Benjaminian "idea" of temporality surrounding the concept of Jetztzeit (now-time) and its corresponding form of subjectivity. Considering the differences regarding the other forms of "production" of temporality and their subjective structures, we will continue to specify the internal workings of the concept of Jetztzeit. To that end, we will consider the contrast between this concept and the concept of Jetztsein (being-now) in relation to the issues of dreaming and childhood under the programmatic task of the "awakening" (Erwachen). To illustrate this articulation we will borrow the concepts of Lebenszeit (life-time) and Weltzeit (world-time) by Hans Blumenberg (1986), but we will structure them in a different way.
\end{abstract}

Key-words: Jetztzeit (now-time). Subjectivity. Childhood. Lebenszeit-Weltzeit (lifetime, world-time). Common-Time.

Después de Kant, pensar la temporalidad sin tener en cuenta una correspondiente configuración de la subjetividad se nos presenta tan absurdo como

\footnotetext{
${ }^{1}$ Cristián Sucksdorf - Doctorando en filosofía en la Universidad Nacional de Lanús. Autor del libro "Del temor a ser tocado. Coeditor del proyecto de Obras Completas de León Rozitchner en la Biblioteca Nacional.
} 
intentar comprender las determinaciones de la vista únicamente en función de la luz, olvidando que opacidad y sombra son también atributos ineludibles de la imagen. Es por esto que la tarea que ahora nos ocupa, reconstruir la idea de la temporalidad en Benjamin a partir del concepto de Jetztzeit, será también, en todo momento, dibujar el perfil de su correspondiente idea de subjetividad. No de otro modo a como la luz y la sombra tejen en nuestra sensibilidad la imagen de las cosas.

Para comenzar intentaremos retener la "imagen panorámica" de este concepto de Jetztzeit tal y cómo se ofrece a la ingenuidad del primer vistazo, antes de que el análisis la oculte para siempre, así como la fachada de una casa -indicaba Benjamin- desaparece cuando atravesamos su umbral. Esta imagen externa del concepto nos permitirá, al adentrarnos en sus determinaciones profundas, "no olvidar lo mejor", esto es: el papel que juega este concepto de Jetztzeit en la "idea" benjaminiana de temporalidad; y por extensión entonces, también de subjetividad.

Pero no buscaremos estas determinaciones profundas para deducir de ellas un imaginario edificio de la idea de temporalidad, sino para invocarla en su nombre, intentando que en el choque de este concepto con otros de otras latitudes se transmute en luz y quemadura esa vaporosa existencia de la idea. Pues pensamos que intentar deducir una idea, en sentido benjaminiano, a partir de la mera funcionalidad de sus conceptos sería como buscar constelaciones en el encandilado cielo del mediodía. Y quizás esto se relacione con la afirmación de Benjamin de que "el método es rodeo"; pues si bien las ideas no pueden ser expresadas en sí mismas, sino a partir de conceptos - que funcionan como mediadores entre ellas y los fenómenos, de modo que sea consumada en dicha mediación "la exposición de las ideas en el medio de la empiria" ${ }^{2}$ - creemos que tampoco la mera descripción de conceptos alcanzaría para dar vida a una idea. Pues el camino de abocarnos sólo al funcionamiento de los conceptos en sí mismos apunta a su conocimiento, pero no a la verdad, que es el ámbito propio de la idea. El modo en que el conocimiento se acerca a la verdad es un símil de esos caminos soñados por Kafka, que se dirigían irrenunciables al castillo, sin acceder a él. Mediante el conocimiento podremos acercarnos a la verdad, pero jamás alcanzarla.

¿De qué modo deberíamos entonces dirigirnos a esa verdad, es decir, a la idea de temporalidad? Volvamos a la analogía benjaminiana entre las ideas y las

2 BENJAMIN, El origen del Trauerspiel alemán, trad. Jorge Navarro Pérez, id., Walter Benjamin Obras, Abada Editores, Madrid, 2006, 11., 1 v., p. 230. 
constelaciones. Podríamos agregar entonces que la noche, en su rapsodia de estrellas y vacío, no podrá poseer constelaciones hasta que el asombro no las dibuje en nuestra fantasía; pues no es el cielo quien cobija constelaciones, sino el deseo, el temor y la tradición. Por esto creemos que acceder a esa idea será posible sólo en tanto la invoquemos bajo nuestro cielo, contraponiendo sus conceptos con aquellos otros que determinan nuestra mirada. Pues las ideas, como los espejos, sólo sugieren el misterio de su rostro en la imagen que nos devuelven del nuestro. De modo que el espacio de las imágenes que esas constelaciones o ideas dibujan sólo podrá ser abierto a nuestra mirada como reflejo de nuestro propio espacio de imágenes. Lo eterno de esa constelación que es la idea benjaminiana sólo relumbrará entonces en la efímera actualidad de cada mirar, es decir en la apertura de ese "mundo de omnilateral e integral actualidad (Aktualität)". Pero esta actualidad que deberá nacerle al tiempo deberá ser también una particular forma de subjetividad que le nazca a la política. Vislumbrar esta relación es lo que ocupará las siguientes páginas.

\section{El umbral del concepto}

Tomemos para comenzar esa "imagen panorámica" del concepto de Jetztzeit como se nos ofrece en su formulación última de las Tesis sobre la filosofía de la historia (Thesen über den Begriff der Geschichte). Lo que en primer lugar notaremos es que vigila su umbral el rostro doble de Jano: plenitud y destrucción. El Jetztzeit se nos presentará entonces como plenitud del tiempo, es decir como un tiempo colmado, pero al mismo tiempo como destrucción del continuum de la historia en tanto que tiempo vacío y homogéneo.

Si hacemos foco en esta cara de la destrucción, encontraremos en ella un desborde del ámbito de lo meramente conceptual. Pues esta destrucción no se da en los términos de una refutación que el concepto de Jetztzeit haría del concepto de tiempo vacío y homogéneo del historicismo. Ya no se trata de interpretar el mundo o la historia. Pues nos advierte Benjamin que el materialista histórico sólo podrá articular este concepto de Jetztzeit al "hacer saltar el continuum de la historia"3, lo que supone por tanto al tiempo vacío y homogéneo.

\footnotetext{
${ }^{3}$ BENJAMIN, Tesis sobre la filosofía del la historia, Madrid, Editora Nacional, 2002, p. 124, tesis XVI.
} 
Pero el hecho de que este enfrentamiento sea "real", es decir que no pueda articularse el concepto de Jetztzeit sin que el continuum histórico sea destruido, no remite al "realismo" de los conceptos, sino a la perspectiva bajo la cual se agrupan a su alrededor los diferentes "elementos" del mundo. ¿En qué consiste esta perspectiva? Podríamos aproximarnos a su vocación a través de la crítica que hace Marx en la primera de las tesis sobre Feuerbach al "materialismo vulgar", según la cual éste "sólo capta la cosa (Gegenstand), la realidad, lo sensible, bajo la forma del objeto (Objekt) o de la contemplación (Anschauung), no como actividad humana sensorial, no como praxis, no de un modo subjetivo." ${ }^{4}$ Si estos conceptos benjaminianos remitiesen a modos opuestos de pensar el tiempo histórico, es decir, si su mundo fuese el de la pura contemplación, su articulación sería posible sin implicar la mutua destrucción. Pero no desde el punto de vista de la praxis, donde los conceptos no refieren a diferentes modos de "pensar" el tiempo histórico, sino de producirlo.

Así, el continuum histórico, ese tiempo vacío y homogéneo, sólo puede ser destruido porque existe, no como mero concepto contemplativo, sino como la forma de producir la Historia de aquellos que dominan, es decir como la instauración de la temporalidad de los que han vencido. $Y$ es entonces por esto que la relación entre el Jetztzeit y el continuum histórico, como dijimos, no consiste en la mera articulación de dos visiones diferentes de la temporalidad, sino en modos antagónicos de producir el tiempo histórico. Quizás por esto diga Benjamin que el Mesías "no viene al mundo sólo como redentor sino como vencedor del Anticristo" ${ }^{5}$, es decir, que el Jetztzeit se manifiesta en su carácter destructivo frente a aquello que se opone a su praxis.

Veamos ahora esa otra cara que se cernía en el umbral del concepto de Jetztzeit, es decir la plenitud. Para Benjamin esta plenitud es la temporalidad de "un presente que no es transición, sino que ha llegado a detenerse en el tiempo". $6 \mathrm{Al}$ materialista histórico se le presenta entonces lo que ha sido como mónada y "reconoce el signo de una detención mesiánica del acaecer, o dicho de otra manera: de una coyuntura revolucionaria en la lucha a favor del pasado oprimido."7

\footnotetext{
${ }^{4}$ MARX, Tesis sobre Feuerbach, en: Escritos de juventud, Buenos Aires, Antídoto, 2006, p. 167.

BENJAMIN, op. cit., p. 112, tesis VI.

Idem, ibidem, p. 124, tesis, XVI.

Idem, ibidem, p. 125, tesis, XV.
} 
A simple vista podría pensarse que esa acción revolucionaria, en tanto hecho empírico, sería el fin del continuum de la historia y su transición, y que colmaría por tanto ese vacío temporal. Pero si miramos atentamente encontraremos que esa "coyuntura revolucionaria" lejos de ser la que hace saltar el continuum de la historia, es, antes bien, su consecuencia. Sólo a partir de la detención mesiánica del continuum del tiempo es que una época determinada puede saltar del curso homogéneo de la historia, y a partir de allí, entonces, ser reconocida la coyuntura revolucionaria en la lucha por redimir el pasado. El vacío de la temporalidad que instaura el continuum histórico no puede ser colmado, por lo que el tiempo pleno deberá ser entonces una temporalidad alternativa al tiempo vacío y homogéneo.

La doble articulación de la plenitud y la destrucción nos ha abierto a las dos principales determinaciones que contornean el umbral, y en este sentido la frontera, del concepto de Jetztzeit: por un lado la existencia de formas irreductibles de "producción de temporalidad" -es decir la temporalidad del Jetztzeit y la del continuum del historicismo- y por el otro su respectiva alternatividad o antagonismo.

Pero hay además un tercer elemento en esta "imagen panorámica" del concepto de Jetztzeit que hemos apenas esbozado. Sólo se manifiesta negativamente, pero su existencia debe ser supuesta para que estos distintos modos de "producción de la temporalidad" no desarrollen su actividad en el vacío. Podemos encontrar en Benjamin la consideración de que la acción productiva, "la creación", no se engendra desde sí misma como autodeterminándose en el vacío, sino que se produce en el enfrentamiento con su objeto. Esto se ve en la cita que hace Benjamin en El París del Segundo Imperio en Baudelaire ${ }^{8}$ y que repite en la "Tesis XP", de una observación que hace Marx ${ }^{9}$ en la Crítica al programa de Gotha. El centro de esa observación de Marx consiste en la afirmación de que "el trabajo no es la fuente [única] de toda riqueza", sino que "la naturaleza es (...) fuente de los valores de uso (...) ni más ni menos que el trabajo", de la que éste, además, sería

8 BENJAMIN, "El París del Segundo Imperio en Baudelaire", trad., J. Aguirre, en: Ensayos II, Editora Nacional, Madrid, 2002, p. 75.

9 Benjamin cita el siguiente fragmento: "Los burgueses tienen razones muy fundadas para atribuir al trabajo una fuerza creadora sobrenatural; pues precisamente del hecho de que el trabajo está condicionado por la naturaleza se deduce que el hombre que no dispone de más propiedad que su fuerza de trabajo, tiene que ser, necesariamente, en todo estado social y de civilización, esclavo de otros hombres." Karl Marx, Glosas marginales al programa del Partido Obrero Alemán (1875), edición digital, Juan Rafael Fajardo, en: http://www.marxists.org/espanol/me/1870s/gotha/gotha.htm, fuente: Carlos Marx, Crítica al Programa de Gotha, Ediciones en Lenguas Extranjeras, Pekín (Beijing), República Popular China, 1979. 
expresión. De modo que toda actividad humana, es decir toda producción y creación, debe ser pensada como inseparable de la materialidad sobre la que se desarrolla y a la que pertenece. Esta copertenencia de la actividad y el objeto - en sentido amplio - la condensa Marx en los Manuscritos del " 44 y en los Grundrisse bajo la imagen de la naturaleza como "cuerpo inorgánico" del ser humano.

Benjamin cita esta observación calificándola como de "excepcional importancia" para el concepto de lo "creativo". Por lo que si suponemos que estas distintas formas de la temporalidad -el tiempo del Jetztzeit o del mesianismo y el del continuum de la historia de la visión del progreso- se dan como "producciones" de temporalidad histórica, podremos entonces suponer que ambas deban darse sobre fondo de, y perteneciendo a, algo que podríamos llamar "materialidad del tiempo histórico", de la que no obstante, no tenemos aún determinación alguna. Nos basta sin embargo la hipótesis de su existencia para avanzar en las determinaciones de los diferentes tipos de "producción de temporalidad histórica" que, creemos, pueden encontrarse y reconstruirse en el pensamiento de Benjamin.

\section{Tiempo y forma de subjetividad}

En Tauerspiel y Tragedia - texto de 1916, cuando Benjamin proyectaba El origen del Trauerspiel alemán - podemos encontrar otras formas de temporalidad diferentes a las dos que en su exterioridad, es decir en su mutua relación limítrofe, hemos presentado.

Quizás lo fundamental que allí encontremos sea la referencia a esa instancia de la temporalidad, aún indeterminada, a la que nos hemos referido como "materialidad del tiempo histórico" y sobre la que debían aplicarse los diferentes modos de producción de la temporalidad. En efecto, con la intención de marcar las diferencias entre la forma de temporalidad de la tragedia y la del Trauerspiel, señala Benjamin que el "tiempo de la historia" (Zeit der Geschichte) - sobre el que deben articularse ambas formas de temporalidad - "es infinito en cualquier dirección y se halla incumplido en todo instante" ${ }^{\prime 10}$. Pero este incumplimiento, esta falta de consumación del tiempo, se da en relación a todo acontecer empírico, en tanto es desde el punto de vista meramente empírico que el tiempo histórico es una mera forma sin consumar. De modo que, dice Benjamin, "la fuerza determinante de la

\footnotetext{
${ }^{10}$ BENJAMIN, Trauerspiel y tragedia, trad. Jorge Navarro Pérez, id., Walter Benjamin Obras, Abada Editores, Madrid, 2007, 11., 2 v., p. 138.
} 
forma histórica del tiempo no puede ser captada plenamente por ningún tipo de acontecimiento empírico"11. Pero hay algo más, agrega que existe una forma de "acontecimiento perfecto" que sí puede consumar el tiempo histórico, sólo que debe ser empíricamente indeterminado, a saber, una idea. Esa idea del tiempo consumado es el "tiempo mesiánico", que en función de las Thesen podemos remitir directamente a la estructura del Jetztzeit.

Con respecto a esta consumación del tiempo histórico es que el "tiempo trágico" y el "tiempo mesiánico" se relacionan. ¿Cuál es entonces la diferencia entre ambos? Lo dice Benjamin con claridad: "El tiempo trágico es al tiempo mesiánico lo que el tiempo consumado individualmente es al tiempo divinamente consumado."12 Ambas formas de temporalidad se presentan entonces como consumaciones del tiempo histórico, pero esta consumación se da de modo diferente en función de la forma de subjetividad con que cada una lo haga. Aún no podríamos decir nada sobre el significado profano de la consumación divina del tiempo, es decir del tiempo mesiánico; veamos entonces la consumación individual del tiempo como tiempo trágico.

\section{Tragedia: el tiempo pleno de los grandes individuos}

¿En qué consiste esta determinación del tiempo trágico como consumación individual? Ya desde el comienzo nos da Benjamin una clave: la unión entre el tiempo histórico y el trágico no se da en el accionar del individuo sin más, sino en las acciones de los "grandes individuos". Es decir que esta consumación debe darse en función de la forma de subjetividad a la que pertenece esa temporalidad trágica. Nos queda entonces por averiguar en qué consiste esta estructura de la subjetividad.

En primer lugar podríamos aventurar que esta "grandeza" no debería darse como una diferencia de grados entre individuos, una cualidad externa a esa composición subjetiva que describiese un continuo infinito - o infinitesimal - como aquella pista de carreras en que la tortuga vence siempre al bueno de Aquiles. Pues en tal caso no existiría un límite certero que contenga dicha forma subjetiva diferenciada de otras. Por lo tanto esta "grandeza" deberá ser aquello que constituya y fundamente la individualidad misma de los "grandes individuos". De modo tal que los "pequeños" y los "grandes individuos" no aparezcan como síntesis, más o menos

\footnotetext{
${ }^{11}$ Idem, ibídem..

12 Idem, Ibidem.
} 
definidas, de una identidad continua -es decir, "lo individual"- sino como formas diferenciadas de la subjetividad. Debemos buscar entonces en lo específico de este tipo de subjetividad.

Quizás haya sido Freud el autor que mejor comprendió esa constitución subjetiva que llamamos "gran individuo" y en la que el héroe trágico tendría su modelo. La descripción de esta forma de subjetividad podemos encontrarla fundamentalmente en dos textos suyos íntimamente relacionados: Tótem y Tabú (1912-3) y Psicología de masas y análisis del yo (1920-1). Este "gran individuo" tendrá entonces su aparición protohistórica como padre de la "horda primitiva", y como caudillo de las "masas artificiales" - cuyo paradigma son la iglesia y el ejércitosu regreso histórico.

Recordemos esquemáticamente este "mito científico". Freud parte del supuesto darwiniano de una existencia pre-histórica de la humanidad organizada en pequeños grupos llamados hordas. Cada horda era regida por un padre omnipotente y violento que reservaba sólo para sí mismo la satisfacción sexual con las mujeres. Los hijos varones, privados del acceso sexual a las mujeres de la horda, quedaban obligados al celibato o a la satisfacción homosexual. En un momento determinado, como fruto de su mutua insatisfacción y en el reconocimiento de la situación compartida, dan muerte al padre y lo devoran. Con ello dan lugar a una nueva sociabilidad basada en ese poder fraternal recientemente conseguido. Pero el componente de amor de la relación con el padre, satisfecho ya el odio con el asesinato, trasmuta el júbilo de la victoria en el dolor del remordimiento unido a la culpa. Esta culpa, sumada a las luchas intestinas e irresolubles por ocupar el lugar dejado por el padre, da lugar a la instauración de la ausencia del padre como ley: la prohibición del incesto. Éstas son, esquemáticamente, las líneas fundamentales del mito con que Freud ilustra el tránsito arcaico de la humanidad desde la prehistoria o naturaleza a la historia o la cultura.

Refiere Freud a esta subjetividad sin límites del padre de la horda primitiva para quien los otros no son más que objetos de satisfacción - la primera psicología individual. Pero ésta, en verdad, es compensada por un tipo particular de psicología colectiva $^{13}$ : la de los hijos-hermanos. Si continuamos la línea de desarrollo de esta "psicología arcaica", encontraremos que tal "psicología colectiva", la de los

${ }^{13}$ Colectiva en un sentido impreciso, pues, como veremos, se constituyen en la relación individual de la identificación con el padre. 
hermanos, no puede ser considerada colectiva en todo momento, sino tan sólo en ese vértigo y vértice que es la rebelión. Pues cuando prevalece la sujeción a la fuerza del padre, es decir mientras existe la horda primitiva, no existen lazos libidinales directos entre los hermanos que sean lo suficientemente fuertes y estables como para constituir una subjetividad colectiva ${ }^{14}$. En esa instancia sólo se da el tipo de lazo que une a cada individuo-hijo con el Individuo-Padre, bajo el signo del temor y el odio, por un lado, y en su complemento ambivalente en la secreta admiración y el amor, por el otro. Sólo en el momento de la rebelión, entonces, aparecerá un modo colectivo de subjetividad, gravitando, aunque más no sea, alrededor de los polos del odio al padre y el amor -deseo- a las madres y hermanas.

Para Freud el héroe de la tragedia griega es el sustituto imaginario de ese padre asesinado en la rebelión fraterna. Sólo que condensa en la unicidad de su persona a los asesinos y a la víctima. Pues el héroe es responsable de su propia muerte. La comunidad fraterna se anonada como coro ${ }^{15}$ para ser mera espectadora, aterrada y compasiva, de su propia acción ${ }^{16}$. Por esto la muerte del héroe es anterior a su vida; pues su vida, cuya materia es la muerte del padre, sólo es la explicación de la culpa trágica. $Y$ es por ello también que, como dice Benjamin, "el héroe muere de inmortalidad". Pues es precisamente la muerte del padre, "la culpa primigenia", una muerte inmortal, que vive eterna como culpa. Por ello el héroe consuma el tiempo, y cada acción determina la totalidad de su tiempo de vida, pues lo hace desde la muerte. La muerte pone sus huevos en la vida para nacer como destino ${ }^{17}$. Y es por ello - nos advierte Benjamin - que a nadie le es posible vivir en este tiempo consumado de la tragedia, pues esa consumación se da a partir de la muerte como origen de la vida.

Tenemos entonces la primera determinación interna de este segundo tipo de "producción de temporalidad histórica" que es el tiempo trágico. Podemos ver entonces que si bien esta temporalidad al igual que la del Jetztzeit es un tiempo

\footnotetext{
${ }^{14} \mathrm{~A}$ no ser los lazos homoeróticos entre los hermanos, que son para Freud los que explican la posibilidad de que se de la unión de fuerzas sobre la que se apoye la rebelión. Pero en tanto que estos lazos no pueden ser prolongados en sí mismos en el deseo de apropiarse de las mujeres de la horda -que para Freud constituye la causa del asesinato del padre- no podrán tampoco fundamentar una psicología colectiva. Sin agregar a esto la dificultad de que instintos sexuales no coartados en su fin contribuyan a formar un vínculo de tipo social.

${ }^{15}$ FREUD, Totem y Tabú, trad. L. López Ballesteros, Biblioteca Nueva, Madrid, 1973, p. 1847.

${ }^{16}$ Cfr., Cristián Sucksdorf, "Para una crítica del heroísmo", Topía, № 62, año XXI, pp.12-13.

${ }^{17}$ Es quizás ese elemento trágico al que se refería Malraux en L' Espoir al decir que lo trágico de la muerte es que convierte la vida en destino.
} 
pleno, consumado, se diferencia de éste en la estructura subjetiva en la que se da, es decir en esa figura del "gran individuo". Para comenzar a comprender profanamente ese tipo de estructura subjetiva del Jetztzeit, esa consumación divina del tiempo, deberemos ver antes las restantes formas de "producción de temporalidad" que creemos pueden encontrarse en el pensamiento de Benjamin.

Repasemos: tenemos hasta aquí una materia indeterminada de tiempo histórico, y dos formas diferentes de lo que hemos llamado "producción de temporalidad", a saber, el tiempo trágico por un lado, y el mesiánico -que hemos referido al Jetztzeit como su forma profana- por el otro. Ambas se caracterizaban por ser formas consumadas del tiempo, pero se diferencian a su vez en su estructura subjetiva: los "grandes individuos" en el tiempo trágico y la forma divina de la consumación en el mesiánico. Y es en función de estos dos parámetros, a saber, la consumación o no del tiempo y la estructura subjetiva que le corresponde, que podemos reconstruir esas diferentes temporalidades.

Así, siguiendo con el planteo de Benjamin en Tragedia y Trauerspiel, podemos encontrar otra forma de temporalidad: el tiempo del Trauerspiel. Esta forma de temporalidad coincide con el tiempo trágico en función de la referencia a los "grandes individuos", manifiesta en la "realeza" de los personajes de los Trauerspiele, pero se diferencia de aquélla por ser una forma no colmada, aunque sin embargo finita, del tiempo.

Pero hay algo más. Y es que este tiempo, dice Benjamin, no es individual, sin ser por ello tampoco una "generalidad histórica"18. Esto no remite tanto a la estructura subjetiva, sino al carácter temporal mismo. Es decir, a que "La generalidad de su tiempo es fantasmagórica, no mítica."19 Habíamos visto que en la tragedia el héroe muere cada vez como forma de actualizar la culpa siempre presente, y que el desarrollo aparentemente lineal de su vida era absorbido en cada momento como una determinación de su muerte en tanto que destino. La consumación de ese tiempo es entonces la forma cíclica del mito. Pero en el Trauerspiel la estructura clásica del mito ha sido rota. ¿De qué temporalidad se trata

\footnotetext{
${ }^{18}$ BENJAMIN, Trauerspiel y tragedia, trad. Jorge Navarro Pérez, id., Walter Benjamin Obras, Abada Editores, Madrid, 2007, 11., 2 v., p. 140

${ }^{19}$ Es fundamental diferenciar en este punto el sentido del carácter "mítico" de esta temporalidad, referido a la estructura cíclica del mito pagano, del sentido de lo mítico de la violencia tal como aparece en Zur Kritik der Gewalt pues en este segundo aspecto la temporalidad fantasmagóricacristiana del Trauerspiel también poseería un carácter mítico.
} 
entonces? Del tiempo cristiano, cuya forma temporal, en palabras de Karl Löwith ${ }^{20}$, puede reducirse a la continuación infinita potencialmente en el interior de uno sólo de esos ciclos del mito pagano. Es por esto que la ley del Trauerspiel es la "repetición", sólo que transformada por la muerte; la continuación de la representación será entonces repetida en los trasmundos. De modo que el "gran individuo", el rey protagonista de los Trauerspiele, será una figura vacía, pues su muerte no es consumación, sino sólo un modo más de existencia: la espectral.

Corresponden entonces dos formas de muerte a cada una de estas formas temporales. La muerte en la tragedia sería una instancia plena, porque en la repetición del sacrificio del héroe la comunidad anonadada en coro recobra su propia mismidad, es decir la asunción de esa muerte como su propia vida; en el Trauerspiel, por el contrario, la muerte es un lugar vacío: la nada que separa a la comunidad de su esencia y que la torna ahora espectral.

Volvamos a la estructura subjetiva que tomamos de Freud. Encontrábamos allí que los "grandes individuos", el "caudillo" de las masas artificiales y el "protopadre" de la horda, tenían como contracara una subjetividad colectiva. Esa colectividad estaba, no obstante, formada por individuos en tanto que se identificaban uno a Uno con ese "gran individuo". Por lo que en ambos casos estábamos ante formas individuales de la subjetividad. Ahora bien, si pensamos que estas dos formas de temporalidad, el tiempo no consumado del Trauerspiel y el consumado de la tragedia, se articulan como tales en función de los "grandes individuos", formas diferentes de temporalidad deberían surgir de la articulación en función de los "pequeños individuos".

Ya hemos visto una forma de tiempo histórico "no consumado", tiempo vacío, del que ahora estamos en condiciones de decir que se articula en función de "pequeños individuos": es el tiempo vacío y homogéneo del continuum de la historia como progreso. Así como el tiempo no consumado del Trauerspiel, articulado en torno a los "grandes individuos", se da como una linealidad temporal interrumpida por la muerte y continuada como repetición espectral, esta temporalidad no colmada, articulada desde la subjetividad de los "pequeños individuos" en el continuum histórico, toma también la forma de una linealidad interrumpida por la muerte -en este caso la minúscula muerte de la vida individual- y continuada en el infinito

\footnotetext{
${ }^{20}$ LÖWITH, Historia del mundo y salvación, Katz, Buenos Aires, 2007, p. 245.
} 
potencial de un "futuro mejor". El lugar de la muerte lo juega aquí el vaciamiento del presente; su forma es la de aquellos célebres versos de Browning: "el presente es el instante en que el futuro se derrumba en pasado". Así, la vida, en ambas temporalidades no colmadas, es interceptada por la muerte y continuada luego de modo diferente. Esta interrupción implica en ambos casos un vaciamiento del tiempo, pero la resolución será diferente: en el Trauerspie/ la imagen espectral de los "grandes individuos" ocupa ese vacío con la traslúcida repetición de su apariencia; en el progreso será la esperanza como "cotidianidad" de los "pequeños individuos" la que se abra desde ese vacío del tiempo, pero no para llenarlo, sino para prolongarlo como aplazamiento; un futuro mejor bajo la forma: "hoy no, mañana".

Pero según esta estructura nos quedaría aún por precisar una cuarta forma de temporalidad. Es decir, aquella que al igual que el tiempo trágico se constituya como temporalidad colmada, pero no en torno a los "grandes individuos" sino a los "pequeños", coincidiendo en ello con el continuum histórico del progreso. $Y$ esta forma de temporalidad plena de los "pequeños individuos" podríamos referirla a la constitución heroica de la modernidad que Benjamin advierte en torno a Baudelaire: el suicidio como pasión fundamental de lo moderno, no ya como renuncia sino como pasión heroica ${ }^{21}$.

La muerte del héroe trágico consumaba el tiempo porque su vida sólo era el despliegue analítico - si puede decirse así - de su muerte, el suicidio del obrero es en cambio un intento imposible de alcanzar la plenitud de un tiempo que se vacía: "la única acción heroica que les quedaba en los tiempos de la reacción a las multitudes maladives"22. De modo que esta forma de "producción de temporalidad" no consiste en la acción del suicidio en sí mismo, es decir, independientemente de todo sujeto y de toda otra estructura temporal, sino sólo en tanto que respuesta articulada desde los "pequeños individuos" a un contexto determinado.

Anota Benjamin en el Libro de los pasajes: "Hacia 1840, el suicidio es común en el imaginario de los trabajadores." ${ }^{23}$ Pero, ¿qué es lo que este contexto tiene de particular para relacionar el trabajo, que es reproducción de la vida, con la muerte? Nos lo aclara Benjamin:

\footnotetext{
${ }^{21}$ BENJAMIN, "El París del Segundo Imperio en Baudelaire", cit., p. 79.

${ }^{22}$ Idem, ibídem, p. 80.

${ }^{23}$ BENJAMIN, Libro de los Pasajes, Akal, Madrid, 2005, p. 728.
} 
Las resistencias que lo moderno opone al natural impulso productivo del hombre están en una mala relación con sus fuerzas. Es comprensible, si el hombre se va paralizando y huye hacia la muerte. Lo moderno tiene que estar en el signo del suicidio, sello de una voluntad heroica que no concede nada a la actitud que le es hostil. ${ }^{24}$

Es decir que esta "solución por el suicidio", que se da desde el nivel individual de los trabajadores, se enmarca necesariamente en una forma de trabajo que se opone al "natural impulso productivo del hombre". Esta forma ha sido definida por Marx en 1844 como "trabajo enajenado" (etnfremdete Arbeit). Y no es casual que en 1846 publicara en Gesellschaftsspiegel un artículo sobre el suicidio, "Peuchet: vom Selbstmord", en el que reseñando las memorias del archivista de la policía de la Restauración, Jaques Peuchet, encontraba en el suicidio el síntoma principal desde la vida privada de la defectuosa organización social, imposible por tanto de solucionar desde los parámetros sociales del capitalismo ${ }^{25}$. Esta forma de trabajo, el trabajo enajenado, constituye entonces la determinación de esos trabajadores como meros individuos, al ser enajenados de su ser genérico (Gattungswesen) por un lado, y en la oposición al "natural impulso productivo del hombre" -que encontraba Benjamin determinando el suicidio "heroico"n-, por el otro.

Pero, ¿de qué modo puede la acción del suicidio constituirse como una salida a la enajenación en su sentido total? Este suicidio se daba como respuesta a una desesperación social, tal como se manifiesta, por ejemplo, en el exhorto que compendia Benjamin ${ }^{26}$ de aquel obrero que antes de suicidarse dejaba una carta abierta llamando a sus "compañeros de sufrimiento a seguirle". Pero este intento libertario del suicidio se articulará desde la misma subjetividad enajenada como individualidad, es decir desde el ser humano convertido sin más en mero "trabajador", separado por tanto de los otros y de ese "cuerpo inorgánico" suyo que es la naturaleza ${ }^{27}$. De modo que ahora podríamos comprender el sentido del suicidio en este contexto como el intento individual, y por ello absolutamente nihilista y en sí mismo alienado, de intentar superar la condición de mercancía aniquilando el propio "valor de uso" en tanto que "trabajador". El suicidio intentaría así colmar el tiempo

\footnotetext{
${ }^{24}$ BENJAMIN, "EI París..." cit., p.70.

${ }^{25}$ MARX, "Peuchet: vom Slbstmord", en: Karl Marx, Eric A. Plaut y Kevin Anderson (eds.), "Karl Marx: vom Selbstmord", ISP, Köln, 2000, p. 60.

${ }^{26}$ BENJAMIN, "EI París...", cit., p. 79.

${ }^{27}$ Esto, en los términos de los Manuscritos del '44, significa la transformación del trabajador en mercancía.
} 
destruyendo, junto con el valor de uso el tiempo abstracto del trabajo cuya expresión maquínica es el reloj.

Pero de lo que aquí se trata no es de una resistencia última, un suicidio colectivo como el de los judíos de Masada, sino de algo como una recidiva, un King Ludd, individual y melancólico, que renaciese a la historia desesperado al verse convertido en máquina. Pero la consumación del tiempo en el suicidio será sin embargo una forma imaginaria, pues no logrará consumarlo más que en una imagen interior, cuando en el vértice de ese "instante de peligro" se condense en recuerdo la imagen de todo lo sufrido. Es cierto que la temporalidad de ese instante individual de peligro no puede ser medida por los relojes, ni abstraída de su vivencia, pero su consumación es como la satisfacción de deseos en el sueño: sólo imagen, la actualización alucinada de una interioridad que no tiene acceso al mundo exterior, y que como tal se desvanece con "el despertar de la muerte".

Tenemos entonces cuatro formas de la temporalidad que representan las determinaciones posibles del tiempo histórico desde el punto de vista de la individualidad. Repasémoslo: a) el tiempo trágico, como tiempo pleno de "grandes individuos"; b) el tiempo del Trauerspiel como tiempo no consumado de "grandes individuos"; c) el tiempo del continuum, como tiempo no consumado o vacío de "pequeños individuos" y d) el tiempo del suicidio como tiempo pleno (aunque imaginario) de "pequeños individuos".

Hemos reconstruido las variantes de "producción" de temporalidad que, creemos, podían encontrarse en el pensamiento de Benjamin y que se diferenciaban de la forma del Jetztzeit. Esta reconstrucción la hemos desarrollado en función de dos ejes: por un lado una noción de temporalidad que subyacía a cada una de ellas en tanto esa temporalidad tendiese a la plenitud o al vaciamiento del tiempo; por el otro la forma subjetiva en que dicha temporalidad se articulase. Por lo demás, esta forma subjetiva consistía en modos de la individualidad que diferenciamos utilizando el esquema freudiano de las "masas artificiales" como "grandes" y "pequeños" individuos. Sin embargo los límites de esta reconstrucción nada nos dice aún de la relación interna entre la concepción plena o vacía del tiempo y la forma de la subjetividad. El problema aquí es que Benjamin no parece decirnos mucho más al respecto de esta relación, que por lo demás será fundamental para poder comprender el funcionamiento interno del Jetztzeit. Pues de este concepto sólo 
tenemos hasta aquí dos determinaciones, a saber, que es un tiempo pleno, por un lado, y que su forma subjetiva no se corresponde con ninguna de las "formas de la individualidad", por el otro.

Para poder entonces comprender el modo en que se articula la concepción del tiempo - vacío o pleno - y la forma de la subjetividad, tomaremos prestado una concepción ajena al pensamiento de Benjamin, pero que parece adaptarse bien a esta constelación de la temporalidad. Esta concepción es la del "tiempo de la vida" (Lebenszeit) y el "tiempo del mundo" (Weltzeit) de Hans Blumenberg ${ }^{28}$. No se trata aquí de dos conceptos diferentes, por un lado el "tiempo de la vida" y el "tiempo del mundo" por el otro, sino de una relación en la temporalidad, de una distancia variable entre dos polos que podría ser entendida como las diferentes variantes concretas de historicidad ${ }^{29}$ del tiempo humano ${ }^{30}$.

\section{Tiempo de la vida y tiempo del mundo}

Decía Jorge Luis Borges ${ }^{31}$ que no hay otros paraísos que los paraísos perdidos; en el mito hebreo, por su parte, esa pérdida es entendida en términos de expulsión. En cambio para Blumenberg esa "expulsión" constituiría cuanto menos un acto innecesario, pues todo paraíso, por su propia naturaleza, se destruiría a sí mismo. Un estado paradisíaco no podría durar más que un instante, luego del cual sus propios límites nos obligarían a salir ${ }^{32}$ de él. De lo contrario el deseo de traspasar esos límites para ampliar nuestro ámbito de experiencia transformaría a nuestros ojos ese Jardín en una prisión florida. Por lo que esa pérdida - la "salida del

${ }^{28}$ BLUMENBERG, Tiempo de la vida y Tiempo del mundo, trad. Manuel Canet, Pretextos, Valencia, 2007.

${ }^{29}$ Recordemos que dice Benjamin, en un muy citado fragmento, que la diferencia entre las imágenes (Bilder) y las esencias (Wesenheiten) de la fenomenología consiste precisamente en la ausencia de índice histórico (historischer Index) en estas últimas, y que el intento de Heidegger de imponer un sentido histórico es infructuoso por su carácter abstracto (Cfr., G.S., V, 577, N 2 a, 6). Dicha "abstracción" de la historicidad heideggeriana que condena Benjamin se debe, a nuestro entender, a la oposición entre el tiempo del Dasein y el tiempo mundano como instancias irreconciliables, como si el Dasein no perteneciese a su vez al mundo, es decir que el suyo es un tiempo sin ahora, sin actualidad y en ese sentido sin esa inervación del mundo en el sujeto que es la "actualidad". Esta crítica a la temporalidad heideggeriana es, por lo demás, el fundamento mismo de esta concepción de la temporalidad que tomamos de Hans Blumenberg.

${ }^{30}$ Pero esta concepción del "tiempo de la vida" y el "tiempo del mundo" cambiará significativamente su funcionalidad al desprenderse de, y articularse sobre, el espacio de imágenes (Bildraum) y lo "originario", y no como en su contexto original del "mundo de la vida" (Lebenswelt). La diferencia se centrará fundamentalmente por el tipo de subjetividad colectiva que, creemos, implican estos conceptos benjaminianos.

${ }^{31}$ BORGES, "Posesión del ayer", en: Obra Poética, Emecé, Buenos Aires, 2008, p. 621.

${ }^{32}$ Cfr., Hans Blumenberg, cit., p. 66. 
paraíso" - en tanto que apertura de los límites de la experiencia, sería además la ganancia de un nuevo mundo. El mundo de la conciencia. Blumenberg se refiere a este "paraíso perdido" en su forma no mitológica, específicamente fenomenológica, como a la salida del mundo de la vida (Lebenswelt). Y esta pérdida sería entonces el precio a pagar por la conciencia. Dice Blumenberg:

En el fondo y en su raíz no se trata de otra cosa que la incipiente divergencia de entre tiempo de la vida y tiempo del mundo, provocada por el desajuste entre el horizonte de las necesidades y el de las condiciones de su satisfacción. ${ }^{33}$

Esta diferencia entre el tiempo de la vida y el tiempo del mundo sería para Blumenberg el origen de la historicidad del hombre.

Pero hay algo más. Y es que Blumenberg utiliza una metáfora -no podía ser de otro modo- para dar cuenta del modo de articulación de ambos tiempos. Tal metáfora entiende al tiempo como una tijera, cuyas dos hojas serían el tiempo de la vida y el tiempo del mundo. De modo que diferentes configuraciones temporales saldrían del cierre o la apertura de dichas tijeras, o también que diferentes constituciones de temporalidad implicarían una mayor o menor apertura. Pero esto se daría con ciertas limitaciones, porque existiría una desproporción constitutiva entre el tiempo de la vida y el tiempo del mundo: la constatación intersubjetiva de que el mundo no ha nacido con nosotros y que moriremos antes de que el mundo termine. Pero de cualquier modo, dentro de este desarreglo constitutivo entre el tiempo de la vida y el tiempo del mundo, según el tipo de relación que se establezca con el mundo - es decir según el sentido que lo constituya -, se tendrá una apertura diferente de las "tijeras del tiempo" histórico ${ }^{34}$. Pues no se da la misma configuración temporal en una sociedad para la que el mundo tiene un comienzo relativamente cercano o un próximo final que entre nosotros, occidentales, para quienes el tiempo del mundo pertenece a una escala imposible de ser comparada, no sólo ya con el tiempo de una vida humana, sino incluso con el de toda la especie.

\footnotetext{
33 Op. cit., p. 67.

${ }^{34}$ Recordemos que no se trata aquí de dos concepciones independientes una de otra, es decir que no habría un "tiempo de la vida" sin un "tiempo del mundo". No es que el "tiempo de la vida" pudiese corresponderse con la concepción de la "nuda vida", sino que la temporalidad de esta última se relacionaría con una apertura y diferencia tal de las "tijeras temporales" que desde el punto de vista del individuo sólo pudiese percibirse un "tiempo de la vida" separado de todo "tiempo del mundo", es decir una vida desnuda de todo mundo.
} 
Intentaremos ahora trasponer, un poco esquemáticamente, estos conceptos a las formas de "producción de temporalidad" histórica que hemos intentado reconstruir a partir del pensamiento de Benjamin.

\section{Las "tijeras del tiempo histórico" y las formas de temporalidad}

Si a partir de esta concepción del tiempo de la vida y del tiempo del mundo, volvemos la vista a aquella característica fundamental que dividía el funcionamiento de las diferentes formas de "producción de temporalidad", es decir al vacío o a la plenitud del tiempo histórico, encontraremos que no se trata sino de la respectiva exacerbación o mitigación de la distancia abierta entre el tiempo de la vida y el tiempo del mundo. De modo que el tiempo vacío, ése que constituía tanto al continuum del historicismo como al Trauerspiel, no sería más que la temporalidad considerada desde la distancia que separa al tiempo de la vida del tiempo del mundo. Su vivencia no se centraría entonces ni en polo uno ni en el otro, sino en la diferencia - en el vacío - que los separa.

Este vacío o separación, sin embargo, se articula de modo diferente en estas dos formas de temporalidad. En el Trauerspiel, esta distancia no se constituye como un tiempo totalmente vacío, pues esa separación entre el tiempo de la vida y el tiempo del mundo es ocupada por la forma "espectral persecutoria" 35 de los "grandes individuos", es decir por una temporalidad de muerte como frontera entre la vida y el mundo. El continuum del progreso, en cambio, mantiene esa distancia entre tiempo de la vida y del mundo como vacío, apenas disimulado tras el velo de la esperanza en la sucesión temporal, es decir en ese mañana que nunca es hoy.

Vemos entonces que el vacío temporal nunca se manifiesta abiertamente, tan sólo se insinúa. Amenazante en la transparencia de los espectros y esperanzado en el aplazamiento del futuro. Pero ambos casos, sin embargo, remiten a una misma constelación de sentido: la del cristianismo ${ }^{36}$.

\footnotetext{
${ }^{35}$ Tomamos este concepto de la obra de León Rozitchner, que lo utiliza en un sentido diferente al de Benjamin, pero que en lo esencial, creemos, complementario.

${ }^{36}$ Brevemente podríamos remitir la temporalidad cristiana a una operación fundamental de vaciamiento del presente histórico. Pues para el cristianismo el presente, concebido como cumplimiento de la promesa, ya ha sucedido en el pasado, es decir con la venida del Cristo. El futuro consistirá entonces en la mera repetición del pasado: la segunda venida del Cristo. La historia es apenas ese "tiempo que resta", tiempo vacío de todo acontecimiento que separa las dos presencias -encarnación y parusía- que caerían por ello mismo fuera de la historia. Se establece así un espacio de tiempo cuya imagen es de la de una semirrecta cuya proyección al infinito consiste en el indefinido aplazamiento del fin, es decir de la irrupción del presente de la presencia, expresado con claridad en el Katechón paulino o la oración Pro mora finis de Tertuliano. La
} 
El tiempo pleno, por su parte, consistirá en alguna forma de contacto o coincidencia entre el tiempo del mundo y el tiempo de la vida. En el caso del tiempo mítico de la tragedia esa coincidencia se logrará entonces al hacer del tiempo del mundo un tiempo de la vida ${ }^{37}$. Pero, ¿cómo es posible esta igualación, si esa certeza intersubjetiva de que el mundo nos antecede y nos precederá -sin excepción algunaconstituye justamente uno de los fundamentos de la vivencia de mundo? Pues remitiendo el tiempo del mundo no a nuestra vida individual sino a la de ese "gran individuo", el héroe, en que se hipostasiaba la comunidad. Y esto sólo es posible porque, como dice Benjamin, la vida del héroe consiste sólo en esa irónica muerte inmortal. La repetición cíclica de esa muerte se abre entonces a la coincidencia con el tiempo del mundo en su cualidad de tiempo mítico. Pues esta muerte del héroe, que en la evocación trágica constituía su vida, no pertenece al héroe en sí mismo y por derecho propio, sino a la comunidad anonadada que los sostiene en el rito. El mito, en su evocación ritual, es entonces el lugar y el momento en que la comunidad anonadada une su propio tiempo de la vida con el tiempo del mundo.

En el caso de ese "heroísmo moderno", el suicidio como intento último de temporalidad plena desde el punto de vista de los "pequeños individuos", la coincidencia se daría de otro modo. Veámoslo.

El suicidio de los trabajadores del siglo XIX, tal como Benjamin lo encuentra en la obra de Baudelaire, consiste precisamente en la decisión última de aniquilar la distancia del tiempo de la vida y del tiempo del mundo. La percepción subjetiva de esa distancia es la desesperación: un abismo que se abre bajo los pies y que, como todos los abismos, canta con voz de sirena. La manifestación objetiva de esa desesperación - es decir de la diferencia creciente entre el tiempo de la vida y el tiempo del mundo - es la imposibilidad de que la acción del individuo ${ }^{38}$, en tanto trabajador alienado, alcance a determinar y transformar algo del mundo; esto es, a producir su vida. Pero esta alienación del trabajador será también, entonces, una alienación temporal: el "trabajador libre", ése que es convertido en pura subjetividad sin objeto, no sólo ha sido "liberado" de su objeto, la naturaleza, sino que también lo

ideología del progreso mantendría la misma estructura temporal cristiana, cambiando sólo el orden valorativo de esa proyección infinita de la historia. Cfr., Karl Löwith, Historia del mundo y salvación, Katz, Buenos Aires, 2007.

${ }^{37}$ Para el ajuste entre el tiempo de la vida y el tiempo del mundo en el tiempo cíclico de los mitos, cfr., Hans Blumenberg, op. cit., p. 63.

${ }^{38}$ Según la descripción de Marx en los Manuscritos de 1844 el trabajador alienado, es decir reducido a una "pura subjetividad sin objeto." 
ha sido de su tradición. Esta tradición es la forma colectiva de unificar, en el instante efímero del rito o la fiesta, el tiempo de la vida y el tiempo del mundo. Pues las tradiciones conectan en el momento de su ejercicio a las diferentes generaciones. En cada acto que la tradición actualiza gravitan como danzando en corro los siglos y las generaciones en que se ha practicado la misma acción. Cada acto es una acción inmemorial, cada hombre sus antepasados. Y no se trata aquí de evocación o repetición, sino de la anulación del tiempo que efectúa lo elemental volviéndose algo eterno y siempre nuevo, así como, decía Borges, quien mira el mar lo ve por primera vez, siempre.

Tenemos entonces una doble enajenación, espacial y temporal, del trabajador. Por un lado la enajenación enfatizada desde el punto de vista espacial, como enajenación de la naturaleza en tanto que objetividad, cuerpo inorgánico, y que incluye todos los niveles de la enajenación que señalara Marx en los Manuscritos - enajenación del objeto, de la actividad y del ser genérico -. Por el otro su énfasis temporal en la enajenación respecto de las generaciones pasadas por la desaparición de la tradición. De modo que el trabajador alienado se encontraría así doblemente separado del mundo. Su ámbito de acción, en tanto individuo alienado, se reducirá a la interioridad de una subjetividad separada de todo objeto, manifiesta en la separación de su vida y actividad de las condiciones de esa vida y la objetividad de dicha actividad.

Pero también esta alienación se da, y es lo que aquí nos interesa especialmente, como separación creciente del tiempo de la vida individual respecto del tiempo del mundo, o para usar la definición de Blumenberg, como "el desajuste entre el horizonte de las necesidades y el de las condiciones de su satisfacción". Y es por este ámbito de acción reducido a la pura subjetividad, que esa distancia entre el horizonte de las necesidades y el de su satisfacción será anulada al precio de anular toda necesidad posible. Lo que se dará en este intento desesperado por instaurar la plenitud del tiempo mediante el suicidio no será, estrictamente hablando, una coincidencia entre el tiempo de la vida y el del mundo, sino la aniquilación de su diferencia. Esa coincidencia sólo crecerá en la pura subjetividad individual, en la atmósfera imaginaria de ese momento final cuando, como decía César Vallejo, "todo lo vivido se empoza, como un charco de culpa, en la mirada" y acaso relumbra 
silencioso el recuerdo, en ese instante de peligro, como constelación última de la vida y el mundo.

Hemos visto, a partir de esta concepción del tiempo de la vida y del tiempo del mundo, el funcionamiento interno de las diferentes formas de "producción de temporalidad". Pero podríamos aún encontrar una determinación más de estas formas temporales de la individualidad, y es que todas ellas se conjugan en relación a la muerte. El tiempo trágico tenía en la muerte del héroe la plenitud de un tiempo cíclico que sostenía la mismidad de la comunidad. En el tiempo del Trauerspiel, en cambio, la muerte interrumpía la linealidad del tiempo transformándola en repetición espectral. En el tiempo del continuum histórico, la muerte, como finitud individual de la vida, vaciaba la temporalidad del presente diluyéndose en la esperanza vacía de un futuro en fuga. Mientras que el tiempo del suicidio aniquilaba en su propio ser la enajenación y la abstracción del tiempo. Es decir, que tanto en los tiempos tendientes a la plenitud, como así también en aquellos tendientes al vacío, la muerte desempeña el papel principal, por lo que quizás no haya que adjudicar ese límite de la muerte a la forma temporal (vacío o plenitud), sino a las formas subjetivas de la individualidad $^{39}$ en torno a las que ésta se articula. Es por esto que la forma subjetiva del Jetztzeit al ser diferente de toda individualidad, no tendría en la muerte, como sí las otras formas de "producción de temporalidad", su contorno y figura última.

Veamos entonces, en función de las diferencias con estas formas de "producción de temporalidad", las determinaciones específicas y el funcionamiento del Jetztzeit.

\section{Sueño e infancia}

Ya en el interior de este concepto de Jetztzeit lo primero que encontramos es su pathos programático: no la corroboración del ser de una realidad temporal, sino la tensión por su deber ser. Y este deber ser consiste en la redención del pasado en el presente efímero de una constelación que arranque, entonces, "eso que ha sido" del dormir de la historia. No para cerrar la realidad a la vigilia del presente histórico, sino para ampliar sus fronteras con el contenido onírico del pasado, así como Freud mediante el análisis de los sueños ampliaba, aunque en el restringido ámbito de la

\footnotetext{
${ }^{39}$ Individualidad que incluye tanto a los "grandes individuos" como a los "pequeños".
} 
inmanencia individual, los dominios de la realidad del yo. Podríamos sintetizar esta tarea programática bajo el lema del "despertar" (Erwachen).

Es entonces bajo esta forma del despertar que se da esa articulación del Jetztzeit en la que lo pasado se unía en una constelación con el presente. Ahora bien, ¿en qué consiste este método del despertar? En primer lugar, en tanto relación con lo onírico, Benjamin diferencia su método dialéctico del método surrealista de un Aragon, pues dice Benjamin en el Passagenwerk, que mientras éste

\begin{abstract}
... se aferraba a los dominios del sueño, se ha de hallar aquí la constelación del despertar. (...) aquí se trata de disolver la "mitología" en el espacio de la historia. Lo que desde luego sólo puede ocurrir despertando un saber, aún no consciente, de lo que ha sido. ${ }^{40}$
\end{abstract}

Y la misma distancia tomará entonces respecto de Jung, que también intentaría mantener el sueño separado del despertar ${ }^{41}$.

Lo que se pone en juego aquí, entonces, es la relación dialéctica, la formación de una constelación, entre el presente como "el instante del despertar" y lo que ha sido como el contenido onírico. Este despertar benjaminiano implicará entonces llevar a la vigilia del presente aquel elemento pasado que había quedado sepultado en el sueño de la historia. Pero, ¿por qué el sueño y el despertar habrían de ser las formas en que se manifestase el método dialéctico mediante el cual lo que ha sido, y es conocido inconscientemente, pueda pasar a ser un conocimiento consciente y, por lo tanto, acceder también al presente?

Si retomamos la metáfora de Blumenberg para la articulación del tiempo de la vida y el tiempo del mundo, quizás podamos comprender en qué términos se da la relación entre el sueño, el despertar y la historia. Habíamos visto que Blumenberg tomaba como metáfora del tiempo histórico la imagen de unas tijeras, cuyas hojas fuesen el tiempo de la vida y el tiempo del mundo, de modo que de la mayor apertura o cierre de esas tijeras obtendríamos diferentes formas de tiempo histórico. Pero si nos mantenemos dentro de esa metáfora de las tijeras y continuamos su análisis, habremos de encontrar entonces un tercer término para que esas tijeras puedan funcionar: el punto en que las hojas de esas tijeras se unen. Pues la forma de las tijeras, su cierre o apertura, depende de dos extremos. En la punta de la tijera tendríamos siempre la mayor apertura, aunque variable en función de la relación de

\footnotetext{
${ }^{40}$ BENJAMIN, Libro de los Pasajes, cit., p. 460, N 1, 9.

${ }^{41}$ Idem, p. 489, N 18, 4.
} 
sus hojas; si recorremos las hojas en sentido inverso encontramos que, sin importar el grado de apertura de esas tijeras, la distancia de las hojas va gradualmente acortándose hasta la coincidencia de ambas en el punto de su articulación, que es por lo demás el que permite el cierre o la apertura de las hojas. Podríamos entonces aceptar (matizando su pathos universalista) la afirmación de Blumenberg de que "Toda experiencia histórica se lleva a cabo con las tijeras ya muy abiertas, y siempre abriéndose más, del tiempo de la vida y del mundo" ${ }^{42}$; pero deberíamos agregar a esto que para que haya tiempo histórico, es decir para que esas "tijeras del tiempo histórico" estén abiertas en uno de sus extremos, deberán, en el extremo opuesto, coincidir sus hojas. Es decir que el tiempo de la vida y el tiempo del mundo deben, para poder abrir la dimensión de la historicidad, coincidir siempre en un momento anterior, y que en este sentido sólo podríamos calificar de pre-histórico.

Veamos entonces cuál es ese momento prehistórico y qué relación puede tener con la metodología del despertar Benjaminiano.

\section{Proceso primario e historia}

Lo que tenemos hasta aquí es que este momento pre-histórico es precisamente aquello que el tiempo histórico "pleno" intentaba re-vivir en la coincidencia del tiempo de la vida y del tiempo del mundo. La forma individual de esa pre-historia nos la ha dado Freud con todo lo referente al proceso primario. Freud consideraba la formación del yo como un lento despliegue que se daba desde la indistinción de una relación simbiótica con la madre ${ }^{43}$ hasta su plena formación final con el Edipo. En ese estado primero supone Freud que surge en el niño una necesidad -tomemos el ejemplo del hambre- manifiesta como una carga psíquica que debe liberarse. Sólo el auxilio de la madre -amamantar al niño- podrá dar satisfacción a esa necesidad, liberando así la tensión psíquica acumulada que será vivida por el niño como placer. Ante el surgimiento de una nueva necesidad, con su correspondiente tensión psíquica a ser liberada, el niño actualiza mediante una alucinación la huella mnémica de esa primera satisfacción, pasando con ello de la simple necesidad al deseo. Este "camino corto" hacia la satisfacción, que la busca como una disposición interna, inaugura entonces una etapa de plena coincidencia

\footnotetext{
${ }^{42}$ BLUMENBERG, Opus cit, p. 68.

${ }^{43}$ FREUD, La interpretación de los sueños (1900), en: Obras Completas, Madrid, Biblioteca Nueva, 1973, pp. 702-713. También véase: Sigmund Freud, Proyecto de una psicología para neurólogos (1895), cit. pp. 229-235.
} 
entre el sujeto y el objeto, es decir esa indistinción, desde el punto de vista del niño, entre él y la madre. Esta indistinción del sujeto y el objeto será también la coincidencia entre esa vida (que aún no puede ser definido como un yo más que en sentido restringido) y el mundo ${ }^{44}$. Sólo después la paulatina desmentida que la alucinación traerá a la descarga de la tensión irá determinando la necesidad de un segundo proceso que imponga la lógica de la realidad, el proceso secundario.

Pero este proceso secundario que instaura el rodeo de la realidad antes de dar curso a la satisfacción alucinada, no suplanta al proceso primario, sino que se superpone a él coartando su despliegue. El proceso primario -la lógica inconsciente del deseo- se mantendrá inconmovible animando por debajo al proceso secundario la lógica de la realidad-, pero sin embargo, a causa de esta coerción sufrida, será reducido su ámbito de acción a la mera interioridad. De allí en más se manifestará sólo en las grietas de la "realidad", apareciendo por perfiles fugaces en el sueño, la locura y lo poético.

Tenemos entonces en el proceso primario la manifestación individual de esa instancia pre-histórica ${ }^{45}$ que buscábamos como coincidencia del tiempo de la vida y el tiempo del mundo. En él esta coincidencia no se daría como el cierre de las "tijeras del tiempo", sino como esa indistinción inicial que posibilita la existencia de la historicidad misma - en la metáfora, la articulación de las "hojas" de las tijeras - y que se daba en el sin-tiempo de esa unidad del niño con la madre. Luego, con el proceso secundario, se abrirá junto con la realidad y la separación entre el yo y el mundo la diferencia entre el tiempo de la vida y el tiempo del mundo como historicidad, dando lugar a formas diferentes de enajenación temporal. Por lo que esta diferencia se dará siempre sobre fondo de la coincidencia, negada y siempre presente, del proceso primario. Es por esto que esa pre-historia no se constituye como un punto del tiempo perdido en el pasado, sino como la actualidad de aquello que, para decirlo con Benjamin, "les nace al pasar y al devenir" ${ }^{46}$, es decir, como la dimensión originaria.

\footnotetext{
${ }^{44}$ Entendamos que no se trata aquí de dos instancias opuestas -el yo y el mundo- que coincidirían en una experiencia sino de una indistinción originaria, fundamento de toda experiencia, de la que surgirían mediante diferenciación los polos del yo y del mundo, manteniéndose sin embargo esa coincidencia en un nivel arcaico, y en tal sentido siempre actual y pasado.

${ }^{45}$ Quizás a esto, poco antes de morir, se refiera Freud al mundo de los neuróticos como a un paisaje prehistórico sostenido en la fuerza de los procesos primarios. Cfr., Sigmund Freud, Conclusiones, ideas, problemas (1938), cit., p. 3431.

${ }^{46}$ BENJAMIN, El origen del Trauerspiel alemán, cit., p. 243.
} 
$Y$ es a partir de aquí, entonces, que podemos comprender el sentido de esa metodología dialéctica del despertar. Pues es en el despertar, como frontera entre la vigilia y el sueño - en términos de Freud, entre el proceso primario y el secundario que podemos acceder a ese fundamento negado que nos constituye, es decir a ese conocimiento inconsciente del que nada sabemos, y del que sin embargo no podemos prescindir.

Sueño e infancia estarán así íntimamente ligados al intento de recuperar el fundamento de nuestra relación con el mundo. En Marx la pérdida de este fundamento aparecía como un distanciamiento o enajenación espacial, aquí lo hemos visto también bajo su forma temporal. Por lo que en el método del despertar podemos encontrar el sentido de esa "plenitud" del tiempo del Jetztzeit, a saber, como coincidencia entre el tiempo de la vida y el tiempo del mundo, es decir como "actualidad". No ya como un intento de cierre de las hojas de esas "tijeras temporales", sino como la reviviscencia de esa pre-historia u origen que en la vida anímica individual se da a través del sueño y los recuerdos de infancia.

Y quizás sea también éste el sentido de esas palabras de Benjamin en las que definía el propósito central de su Passagenwerk como el intento de contar "Lo que encuentra el niño ( $y$ el hombre en un vago recuerdo) en los viejos pliegues del vestido en los que se metía al aferrarse a la falda de la madre" ${ }^{47}$. Eso que el niño ve en la falda de su madre -y que el adulto apenas puede vislumbrar en lo oscuro del recuerdo- es entonces esa lógica primaria del deseo inconsciente como fundamento de la relación con el mundo, y que, precisamente por ello, no puede ser accesible a la consciencia. Sólo el sueño nos entregará, por perfiles, restos de esa lógica primaria; pero relegados al encierro del dormir, esos sueños, sueños son. Esta forma individual, por lo tanto, no podrá nunca superar en la vigilia de la consciencia la escisión respecto de su fundamento inconsciente. La locura logrará imaginariamente la unificación de ambos dominios al reducir en su delirio el tiempo del mundo al de la propia vida, como puede encontrarse en la forma inocente de un Schreber o en la monstruosa de un $\mathrm{Hitler}^{48}$. Es por esto que el método benjaminiano del despertar no puede darse en el ámbito del individuo, pues, como hemos visto, ése era sólo un despertar "en el sueño de la muerte".

\footnotetext{
${ }^{47}$ BENJAMIN, Libro de los Pasajes, cit., p. 397, K 2, 2.

${ }^{48}$ BLUMENBERG, op. cit., pp. 71-74.
} 
Por esta razón, esa forma originaria de la temporalidad en que coinciden el tiempo de la vida y el tiempo del mundo y que Benjamin ha llamado Jetztzeit, no puede darse en los estrechos límites del individuo. Ese despertar que constituye al Jetztzeit será así un despertar al sueño colectivo, es decir a la historia. Veamos entonces de qué modo puede articularse ese "despertar a la historia".

\section{Del Jetztsein al Jetztzeit}

Dentro de esta forma del "despertar a la historia" encontramos en el Libro de los Pasajes una diferenciación que quizás nos ayude a comprender mejor el funcionamiento del Jetztzeit. Plantea Benjamin la necesidad de que el método dialéctico sea justo no sólo con "la correspondiente situación concreta de su objeto", sino también con la del interés por ese objeto ${ }^{49}$. Es decir, en el ámbito primero de ese vuelco dialéctico que abre el pasado a la posibilidad de constituir una constelación con el ahora. Esta apertura es precisamente el interés por una época, cuya capacidad para hacer presente ese componente pasado será la "prueba de verdad" de su accionar.

Podríamos decir entonces, parafraseando a Marx, que en ese interés se da subjetivamente el objeto pasado que ha encontrado su camino al presente, pues "este interés se siente a sí mismo preformado en aquel objeto (...) [pero además] siente ese objeto concretizado en él mismo, siente que lo han ascendido de su ser de antaño a la superior concreción del ser-actual (Jetztsein) (¡del estar-despierto!)”50. De modo que, análogamente, en este ser-actual (Jetztsein), se da objetivamente el sujeto pasado que ha encontrado su camino al presente. Pero este camino no es aún la plenitud de esa constelación, en que el pasado llega a ser lo que siempre ha sido al relumbrar fugaz en el ahora, porque este ser-actual, dice Benjamin, "no es en absoluto el ser-actual del tiempo-actual [del Jetztzeit], sino uno a sacudidas, intermitente" ${ }^{\prime 51}$.

¿Qué ha de ser, entonces, lo que diferencie ambas instancias, lo que haga de la actualidad del ser-actual una forma aún imperfecta, intermitente, del Jetztzeit? Si el interés a partir del cual una época se vuelve actual no implica por sí mismo que esa época relumbre ya en el presente, hará falta entonces todavía algo más para

\footnotetext{
${ }^{49}$ Cfr., op. cit., p. 397, K 2, 3.

50 Idem ibídem

51 Idem, ibidem.
} 
transformar ese interés en una época pasada en la acción que la salve, es decir la "explosión" mediante la cual el ser-actual [Jetztsein] alcanza la condición de tiempoactual, de Jetztzeit.

\section{Cuerpo común y tiempo común}

La actualidad del ser-actual será una mayor concreción del objeto histórico - y también en cierto modo del sujeto, ya que serán las acciones objetivadas de las generaciones pasadas lo que constituya ese objeto histórico -. Pero, ¿en qué sentido es que esa realidad pasada, y evocada ahora en el interés, puede ser más concreta y actual que en el momento mismo de su existencia? Dirá Benjamin que a través de la condensación [Verdichtung] creciente de su realidad. La dinámica de esta condensación, por medio de la cual esa realidad pasada es enriquecida y complejizada por el presente que la actualiza, es en todo similar al concepto freudiano de condensación, en virtud de la cual el contenido manifiesto del sueño será "pobre y lacónico en comparación con la amplitud y la riqueza de las ideas latentes" ${ }^{2}$. Sólo el presente definirá entonces el valor que una experiencia histórica pasada -e incluso olvidada- pueda llegar a tener, y en ese sentido redefinirá también sus límites.

Pero habíamos visto que el mero interés en un objeto histórico no alcanzaba para instaurar a este último en el Jetztzeit. El interés caería más cerca del sueño que del despertar; pues retomando como actuales los restos olvidados de la experiencia, el interés intenta reconfigurar con ellos una imagen que exprese el nivel inconsciente del deseo, es decir de esa lógica del proceso primario. El Jetztzeit, en cambio, estará dentro de los inasibles límites del despertar; no ciertamente en esa plena vigilia del mediodía de la consciencia, donde las sombras de las cosas dibujan contornos indeclinables, sino dentro de las fronteras crepusculares del instante del despertar, cuando aún nos encontramos ante el extraño mundo que el proceso primario deja tras de sí al bajar la nocturna marea del sueño. Pero entonces, nuevamente debemos preguntarnos por aquello que permite ese pasaje, a través del "interés", del ser-actual al tiempo-actual (del Jetztsein al Jetztzeit). Y con claridad vemos que es el proceso del despertar que corresponde a ese sueño colectivo que

\footnotetext{
${ }^{52}$ FREUD, La interpretación de los sueños, cit. p. 517.
} 
es la historia. Por lo que tenemos aquí, una primera determinación del despertar: éste debe darse también en una forma de subjetividad colectiva.

En el instante del despertar individual -llamémoslo fisiológico- el cuerpo que duerme conjuga en el vértice de ese instante el mundo del deseo inconsciente del sueño, del proceso primario, con el de la realidad, es decir del proceso secundario. Pero la misma estructura del aparato psíquico, que se fundamenta precisamente en la escisión de ambos, obrará para que aquello vislumbrado en la penumbra del despertar sea olvidado en la vigilia, así como la luz del sol oculta las estrellas al clarear el día. El despertar colectivo que se corresponde con el pasaje al Jetztzeit, en cambio, implicará la prolongación de ese elemento recuperado en el ahora de su aparecer. Pues ese despertar no es transición entre un estado y otro, sino la radical aniquilación de esa escisión. Es por eso que este proceso del despertar colectivo como tiempo-ahora (como Jetztzeit) se define como destrucción de la sucesión y ensanchamiento del presente.

Ahora bien, si en el proceso individual del despertar, la estructura escindida históricamente del aparato psíquico -alienada diríamos con Marx- era la que determinaba que vigilia y sueño sólo se tocaran en el olvido, ¿cuál será la instancia equivalente en el despertar colectivo que, contrariamente, permita y determine la anulación de distancia y sucesión en la detención dialéctica del "ahora"? Esa instancia ha de ser el cuerpo del colectivo.

Pues así como el aparato psíquico, en tanto materialidad de la escisión, y en tal sentido como limitación de la "individualidad", generaba con el olvido la conservación de la distancia entre los procesos primarios y secundarios, el carácter corporal-libidinal $^{53}$ (leibhaft) del colectivo, como lo describe Benjamin en su ensayo sobre el surrealismo ${ }^{54}$, será el sustrato de la síntesis de ambos mundos. Síntesis que se manifestará, en primer lugar, como la apertura del espacio de imágenes (Bildraum) del que nos habla Benjamin.

Entonces la apertura de ese espacio se dará a partir de dos escenarios, que podríamos agregar, se corresponden con las dos instancias humanas en que hemos visto se daba la alienación, esto es, espacial y temporalmente. La forma espacial de

\footnotetext{
${ }^{53}$ Agregamos el adjetivo "libidinal" para denotar la diferencia conceptual que entraña la elección de la palabra alemana "Leib" en oposición a "Körper", puesto que no existe equivalente para esta distinción en español. Éste, por lo demás, es el camino seguido por Merleau-Ponty para desarrollar el concepto husserliano del "Leib".

${ }^{54}$ Cfr., Walter Benjamin, El surrealismo, cit., 1l., 2 v., p. 316.
} 
apertura se daría a través de "descubrir en el espacio de lo que es la actuación política el espacio integral de las imágenes" 55 ; la forma temporal se nos manifiesta en un comentario del Libro de los pasajes: "Acercarse así a lo que ha sido, no significa, como hasta ahora, tratarlo de modo histórico, sino de modo político, con categorías políticas" ${ }^{\prime 6}$. De modo que es a través de la política que ambas dimensiones, el espacio de las imágenes o Bildraume y el tiempo-ahora o Jetztzeit, se encuentran como actualidad (Aktualität). Pero esta "acción política" no es una acción más entre otras que pueda ejercer contingentemente cada individuo, sino aquella que fulgura como su posibilidad más peculiar. $Y$ en este sentido, como única existencia práctica del cuerpo colectivo. De modo que sólo existirá tal cuerpo colectivo en su acción política, esa que espacialmente comienza a partir de la formación de un espacio de imágenes, mientras que temporalmente será el emerger de un "tiempo común", es decir la constelación que anula las distancias ente el ahora y lo que ha sido en el Jetztzeit.

Y ahora podemos ver con claridad cuál era esa "forma subjetiva" diferente de los "grandes" y "pequeños individuos", que debía articular el Jetztzeit junto a la "plenitud" temporal: el cuerpo-libidinal colectivo como rostro profano de esa subjetividad "divina". Su divinidad, es claro, no consistirá en otra cosa que en la oscura autopercepción de lo absoluto de su potencia.

Pero hay algo más. Y es que el espacio de imágenes debe conjugarse con el cuerpo colectivo y, aniquilándose dialécticamente, pasar a conformar un espacio corporal (Leibraum). Este proceso es similar al que anteriormente vimos con respecto a la forma temporal, como el pasaje del "interés" del ser-actual (Jetztsein) a su encarnación en el cuerpo-libidinal colectivo, ahora bajo la forma de Jetztzeit. ¿Qué es entonces esta encarnación espacial y temporal que se manifiesta como acción política y constitución del cuerpo colectivo? Pues ese momento en que, según nos cuenta Benjamin, la fiesta y el pánico se reconocen y hermanan en un abrazo, es decir el levantamiento revolucionario, o, por mejor decir, la revuelta, pues la revolución será el resultado final de esa encarnación: el tiempo-ahora (Jetztzeit) y el espacio corporal (Leibraum) inervados en el cuerpo colectivo: un relámpago de tiempo que ilumina entonces la noche cerrada de la historia, y anuncia con el silencio de su luz la atronadora irrupción de la descarga revolucionaria. Sólo

\footnotetext{
${ }^{55}$ Op. cit., p. 315.

${ }^{56}$ Walter Benjamin, Libro de los pasajes, cit., p. 397, K 2, 3.
} 
entonces, podríamos decir siguiendo a Benjamin, la realidad se podrá superar a sí misma; pues sólo encontrará en la revolución, entendida como la inervación del cuerpo colectivo y el mundo, ese vértice fugaz en que el mundo y la vida se miran a los ojos.

\section{REFERÊNCIAS}

BENJAMIN, Walter: Gesamelte Schriften I (R. Tiedemann, y H. Schweppenhäuser, eds.), Frankfurt am Main, Suhrkamp, 1991. 1991.

: Gesamelte Schriften IV (T. Rexroth, ed.), Frankfurt am Main, Suhrkamp,

: Gesamelte Schriften V (R. Tiedemann, ed.), Frankfurt am Main, Suhrkamp, 1991.

: "El origen del Trauerspiel alemán" (trad. Jorge Navarro Pérez), en Walter Benjamin Obras, I. 1., v. 1, Madrid, Abada Editores, 2006.

: "Trauerspiel y tragedia",1l., 2 v, Walter Benjamin Obras, Madrid, Abada Editores, 2007.

: Libro de los pasajes, Madrid, Akal, 2005.

: "Tesis sobre la filosofía del la historia", en Ensayos IV, Madrid, Editora Nacional, 2002.

: "El París del Segundo Imperio en Baudelaire", en Ensayos II, Madrid, Editora Nacional, 2002.

: Ensayos III, Madrid, Editora Nacional, 2002.

BLUMENBERG, Hans: Tiempo de la vida tiempo del mundo, Valencia, Pretextos, 2007.

FREUD, Sigmund: "Tótem y Tabú" (trad. L. López Ballesteros), en Obras Completas II, Madrid, Biblioteca Nueva, 1973.

: "Proyecto de una psicología para neurólogos" (trad. L. López Ballesteros), en Obras Completas I, Madrid, Biblioteca Nueva, 1973.

: "La interpretación de los sueños", cit.

LÖWITH, Karl.: Historia del mundo y salvación, Katz, Buenos Aires, 2007.

LÖWY, Michael: "Walter Benjamin y el surrealismo, historia de un encantamiento revolucionario", en Acta poética, 28 (1-2), México, UNAM, 2007, pp. 75-92. 
MARX, Karl: "Manuscritos económico-filosóficos de 1844", en: Escritos de juventud, Buenos Aires, Antídoto, 2006.

: Glosas marginales al programa del Partido Obrero Alemán (1875), edición digital, Juan Rafael Fajardo, en http://www.marxists.org/espanol/me/1870s/gotha/gotha.htm.

: Marx-Engels Werke 40 (MEW), Berlin, Dietz Verlag, 1968.

:"Peuchet: vom Slbstmord", en Karl Marx (Eric A. Plaut y Kevin Anderson, eds.), Karl Marx: vom Selbstmord, Köln, ISP, 2000.

ROZITCHNER, León: La Cosa y la Cruz, Buenos Aires, Losada, 1996.

: Materialismo ensoñado, Buenos Aires, Tinta limón, 2011.

SCHMITT, Carl: Hamlet o Hécuba, Valencia, Pretextos-Universidad de Murcia, 1994.

SCHOLEM, Gerschom: Walter Benjamin, historia de una amistad, Buenos Aires, Sudamericana, 2008.

: Los nombres secretos de Walter Benjamin, Madrid, Trotta, 2004.

WEIGEL, Sigrid: Body- and Image-space, London-New York. Routledge, 2005. 